\title{
A low cost solution for post-biopsy complications using available RFA generator and coaxial core biopsy needle
}

Type: Article

\section{Abstract:}

Percutaneous image-guided needle biopsy is typically performed in highly vascular organs or in tumours with rich macroscopic and microscopic blood supply. The main risks related to this procedure are haemorrhage and implantation of tumour cells in the needle tract after the biopsy needle is withdrawn. From numerous conducted studies, it was found that heating the needle tract using alternating current in radiofrequency (RF) range has a potential to minimize these effects. However, this Solution requires the use of specially designed needles, which Would make the procedure relatively expensive and complicated. Thus, we propose a simple solution by using readily available coaxial core biopsy needles connected to a radiofrequency ablation (RFA) generator. In order to do so, we have designed and developed an adapter to interface between these two devices. For evaluation purpose, we used a bovine liver as a sample tissue. The experimental procedure was done to study the effect of different parameter settings on the size of coagulation necrosis caused by the RF Current heating on the subject. The delivery of the RF energy was varied by changing the values for delivered power, power delivery duration, and insertion depth. The results showed that the size of the coagulation necrosis is affected by all of the parameters tested. In general, the size of the region is enlarged with higher delivery of RF power, longer duration of power delivery, and shallower needle insertion and become relatively constant after a certain value. We also found that the solution proposed provides a low cost and practical way to minimizes unwanted post-biopsy effects.

\begin{tabular}{|c|c|}
\hline Author & $\begin{array}{l}\text { - Azlan, C. A. } \\
\text { - Nasir, N. F. M. } \\
\text { - Faifizul, A. A. } \\
\text { - Ng, K. H. } \\
\text { - Abdullah, B. J. J. }\end{array}$ \\
\hline Source & Australasian Physical \& Engineering Sciences in Medicine \\
\hline ISSN & 0158-9938 \\
\hline DOI & - \\
\hline Volume (Issue) & $30(4)$ \\
\hline Page & $288-291$ \\
\hline Year & 2007 \\
\hline
\end{tabular}

Keyword:

RFA, Biopsy, cauterization, ablation, percutaneous liver-biopsy, radiofrequency cauterization, fibrin sealant, track, hemorrhage 
Please Cite As:

AZLAN, C. A., NASIR, N. F. M., SAIFIZUL, A. A., FAIZUL, M. S., NG, K. H. \& ABDULLAH, B. J. J. 2007. A low cost solution for post-biopsy complications using available RFA generator and coaxial core biopsy needle. Australasian Physical \& Engineering Sciences in Medicine, 30, 288-291.

URL:

- http://apps.webofknowledge.com search via Accession No >> 000259032900009

- http://www.scopus.com/inward/record.url?eid=2-s2.038649112016\&partnerlD=40\&md5=f5db0d1b760515ff3b2316a752d95c6e

- http://www.springerlink.com/content/n5v70328469443vl/

- http://www.ncbi.nlm.nih.gov/pubmed/18274069 